\title{
Lyn Kinase Regulates Mesolimbic Dopamine Release: Implication for Alcohol Reward
}

\author{
Stuart L. Gibb, ${ }^{*}$ Jerome Jeanblanc, ${ }^{\star}$ Segev Barak, Quinn V. Yowell, Rami Yaka, and Dorit Ron \\ Ernest Gallo Research Center, Department of Neurology, University of California, San Francisco, Emeryville, California 94608
}

We report here that the Src family tyrosine kinase Lyn negatively regulates the release of dopamine (DA) in the mesolimbic system, as well as the rewarding properties of alcohol. Specifically, we show that RNA interference-mediated knockdown of Lyn expression results in an increase in KCl-induced DA release in DAergic-like SH-SY5Y cells, whereas overexpression of a constitutively active form of Lyn (CA-Lyn) leads to a decrease of DA release. Activation of ventral tegmental area (VTA) DAergic neurons results in DA overflow in the nucleus accumbens (NAc), and we found that the evoked release of DA was higher in the NAc of Lyn knock-out (Lyn KO) mice compared with wild-type littermate (Lyn WT) controls. Acute exposure of rodents to alcohol causes a rapid increase in DA release in the NAc, and we show that overexpression of CA-Lyn in the VTA of mice blocked alcohol-induced $(2 \mathrm{~g} / \mathrm{kg})$ DA release in the NAc. Increase in DA levels in the NAc is closely associated with reward-related behaviors, and overexpression of CA-Lyn in the VTA of mice led to an attenuation of alcohol reward, measured in a conditioned place preference paradigm. Conversely, alcohol place preference was increased in Lyn KO mice compared with Lyn WT controls. Together, our results suggest a novel role for Lyn kinase in the regulation of DA release in the mesolimbic system, which leads to the control of alcohol reward.

\section{Introduction}

Lyn is a nonreceptor protein tyrosine kinase (PTK) that belongs to the Src family of PTKs. Lyn is expressed in the adult brain (Umemori et al., 1992; Chen and Leonard, 1996); however, information regarding its role in the CNS is limited. Specifically in cortical neurons, Lyn was shown to directly interact with and upregulate the activity of $\mathrm{Na}^{+} / \mathrm{K}^{+}$ATPase by phosphorylating its $\alpha 3$ subunit (Wang and $\mathrm{Yu}, 2005$ ). Umemori et al. (2003) proposed that Lyn negatively regulates the NMDA receptor (NMDAR) activity, whereas Metere et al. (2006) reported an activation of Lyn in striatal synaptosomes and in the striatum in vivo after overstimulation of NMDAR by exposure to the excitotoxin quinolinic acid. A link between Lyn and the AMPA receptor (AMPAR) has also been suggested. Specifically, stimulation of AMPAR was shown to result in the protection of cerebellar and hippocampal neurons against neuronal cell death through mechanisms involving the activation of Lyn (Wu et al., 2004). In the cerebellum, Lyn was shown to directly associate with the glutamate receptor 2 (GluR2) subunit of the AMPAR and to partici-

\footnotetext{
Received 0ct. 22, 2010; revised Nov. 27, 2010; accepted Dec. 12, 2010.

This work was sponsored by the Department of the Army under Award No. W81XWH-08-1-0004. The U.S. Army Medical Research Acquisition Activity, 820 Chandler Street, Fort Detrick, MD 21702-5014, is the awarding and administering acquisition office. This work was also supported by the State of California Office for Medical Research on Alcohol and Substance Abuse through the University of California. We thank Madeline Ferwerda, and Drs. Billy Chen, Sebastien Carnicella, Viktor Kharazia, and Garret Stuber for technical assistance.

*S.L.G. and J.J. contributed equally to this work.

Correspondence should be addressed to Dorit Ron, The Gallo Research Center, 5858 Horton Street, Suite 200, Emeryville, CA 94608. E-mail: dron@gallo.ucsf.edu.

J. Jeanblanc's present address: Faculté de pharmacie, Université de Picardie Jules Verne, Amiens, France.

R. Yaka's present address: The Institute of Drug Research, School of Pharmacy, Faculty of Medicine, The Hebrew University of Jerusalem, Jerusalem, Israel.

DOI:10.1523/JNEUROSCI.5540-10.2011

Copyright $\odot 2011$ the authors $\quad 0270-6474 / 11 / 312180-08 \$ 15.00 / 0$
}

pate in the AMPAR-mediated upregulation of the BDNF via the activation of the mitogen-activated protein kinase pathway (Hayashi et al., 1999). However, Hayashi et al. (1999) also showed that activation of glutamate receptors induces the phosphorylation of the GluR2 subunit of the AMPAR by Lyn, which leads to the internalization of the subunit (Hayashi and Huganir, 2004).

Interestingly, unlike other Src PTKs that positively modulate cellular functions (Palacios and Weiss, 2004; Salter and Kalia, 2004), Lyn plays a unique inhibitory role in various systems (Xu et al., 2005). For example, Lyn negatively regulates integrin signaling in neutrophils (Pereira and Lowell, 2003), as well as mast cell proliferation (Hernandez-Hansen et al., 2004) and B-cell activation (Scapini et al., 2009).

Ohnishi et al. (2001) previously showed that the global inhibition of Src PTK activity in PC12 cells results in the increase in calcium-dependent release of dopamine (DA), suggesting an inhibitory role of a Src-PTK in DA release. Activation of ventral tegmental area (VTA) DAergic neurons causes an elevation of DA overflow in the nucleus accumbens (NAc) (Schultz, 2007; Grace, 2008), and the rewarding properties of abused drugs including alcohol (ethanol) result from the increase in the level of synaptic DA in the NAc (Gonzales et al., 2004; Hyman et al., 2006).

Here, we set out to test the hypothesis that Lyn negatively regulates DA release, and, if so, we aimed to test the consequences of the inhibition of DA neurotransmission on the rewarding properties of ethanol.

\section{Materials and Methods}

Reagents. Quinine (Q1250), saccharin (S6047), retinoic acid (R2625), and monoclonal anti-tyrosine hydroxylase (TH) antibodies (T2928) were purchased from Sigma. The shuttle vector pShuttle2, adenovirus backbone vector pAdeno-X, Adeno-X maxi purification kit, Adeno-X rapid titer kit, lentiviral expression vector pLVX-IRES-ZsGreen 1, lenti-X 
293T cells, lenti-X HT packaging mix, lenti-phos HT transfection reagents, and polyclonal anti-ZsGreen antibodies (632474) were purchased from Clontech. Anti-Lyn polyclonal antibody (2732) was purchased from Cell Signaling Technology. Lipofectamine 2000, DMEM, nonessential amino acids, $10 \%$ BIS-Tris gels, anti-phospho Src (Y418) polyclonal antibody (44660G), Alexa Fluor-594-labeled donkey anti-mouse, and Alexa Fluor-488 labeled donkey anti-rabbit were purchased from Invitrogen. Anti-green fluorescent protein (GFP) monoclonal antibody (sc-9996), antiglyceraldehyde-3-phosphate dehydrogenase (GAPDH) polyclonal antibody (sc-25778), anti-actin polyclonal (sc-1616) antibody, and the horseradish peroxidase-conjugated secondary antibodies were purchased from Santa Cruz Biotechnology. ${ }^{3} \mathrm{H}-\mathrm{DA}$ was purchased from GE Healthcare, and Scintisafe from Fisher Scientific. PP2 [(4-chlorophenyl)-7-( $t$-butyl) pyrazolo[3,4-d]pyrimidine] was purchased from EMD Biosciences. The shuttle vector pRNAT/HI was purchased from Genscript. Quikchange lightning Site-Directed Mutagenesis Kit was purchased from Stratagene. Fetal bovine serum (FBS) was purchased from Hyclone. Complete miniprotease inhibitor was purchased from Roche, and the protein quantification BCA assay kit from Pierce. Nitrocellulose membranes were purchased from Millipore.

Animals. Male C57BL/6 mice and mating pairs of Lyn heterozygote (Lyn HET) mice (Hibbs et al., 1995) were purchased from Jackson Laboratories. Lyn HET mice (129/Sv × C57BL/6 mixed background) were mated in-house to generate F1 wild-type littermate (Lyn WT), knock-out (KO), and HET mice. F1 HET mice were then mated to generate F2, F3, and F4 Lyn WT and KO mice. Eight- to 16-week-old male mice were used in the studies. At the age the mice were used for the behavioral experiments, we did not observe any developmental or behavioral deficits in the Lyn KO mice compared with Lyn WT mice. Animals were individually housed under a $12 \mathrm{~h}$ light/dark cycle, with lights on at 7:00 A.M. and food and water available ad libitum. Ethanol-naive mice were used for each experiment. Experimental protocols were approved by the Ernest Gallo Clinic and Research Center Institutional Animal Care and Use Committee and were conducted in agreement with the Guide for the Care and Use of Laboratory Animals by the National Research Council.

Construction and preparation of adenovirus expressing short-hairpin RNA targeting Lyn. A short-hairpin RNA (shRNA) sequence targeting Lyn (sense, 5'GAT CCC AGA CTC AAC CAG TAC GTA ATT GAT ATC CGT TAC GTA CTG GTT GAG TCT TTT TTT CCA AA 3'; antisense, 5' AGC TTT TGG AAA AAA AGA CTC AAC CAG TAC GTA ACG GAT ATC AAT TAC GTA CTG GTG AGT CTG G 3') was created based on a sequence reported by Ptasznik et al. (2004). A scrambled (SCR) version of the shRNA sequence (sense, 5' GATC CCA ATG CAT GAC CAA CTC AGA TTG ATA TCC GTC TGA GTT GGT CAT GCA TTT TTT TTC CAA A 3'; antisense, 5' AGC TTT TGG AAA AAA AAT GCA TGA CCA ACT CAG ACG GAT ATC AAT CTG AGT TGG TCA TGC ATT GG 3') was used as a control. Synthesized strands were annealed using a thermal cycler and ligated into the shuttle vector pRNAT/HI. The cassette encoding the shRNA sequence and expression sequence for GFP was subcloned into the adenovirus backbone vector pAdeno-X using the I-Ceu I and PI-Sce I restriction sites. pAdeno-X recombinant adenoviruses (AdvshLyn and Adv-SCR) were transfected into HEK 293 cells using Lipofectamine 2000. Adenoviruses were purified using Adeno-X maxi purification kits and titered with Adeno-X rapid titer kits (Clontech) as per the manufacturer's instructions.

Construction and preparation of adenovirus and lentivirus overexpressing CA-Lyn. Full-length Lyn was cloned from rat cerebellum cDNA ( $87 \%$ identity to the human sequence and $94 \%$ identity to the mouse sequence) and ligated into the shuttle vector pShuttle2. This construct was used as a template for site-directed mutagenesis (Quikchange Lightning Site-Directed Mutagenesis Kit) of tyrosine 508 to phenylalanine (Y508F) generating the constitutively active enzyme (CA-Lyn) (Harder et al., 2001). CA-Lyn was then subcloned to the adenovirus backbone vector. pAdeno- $\mathrm{X}$ recombinant CA-Lyn adenovirus was transfected into HEK 293 cells using Lipofectamine 2000. Virus purification and titration was performed as described above.

To create a lentivirus expressing CA-Lyn (LV-CA-Lyn), the constitutively active kinase was subcloned into the bicistronic lentiviral expression vector pLVX-IRES-ZsGreen1. A lentivirus expressing ZsGreen1 (LV-ZsGreen) was created as a control. For production of recombinant lentiviruses, pLVX vectors were cotransfected with packaging vectors into lenti-X 293T cells with lenti-X HT packaging mix using lenti-phos HT transfection reagents. Medium was exchanged the following day and collected $48 \mathrm{~h}$ later. Lentivirus was concentrated by ultracentrifugation in Beckman Ultra-Clear tubes (catalog \#344058) at 90,000 $\times g$ for $90 \mathrm{~min}$ at $4^{\circ} \mathrm{C}$ using a SW-32Ti rotor and a Beckman Coulter LE-80K ultracentrifuge (Beckman Coulter). Medium was removed, and the lentivirus pellet was resuspended in $\mathrm{Ca}^{2+} / \mathrm{Mg}^{2+}$ free PBS. LV-CA-Lyn and LV-GFP were titered according to the procedure of Tiscornia et al. (2006).

Cell culture. HEK293 and SH-SY5Y cells were cultured in DMEM containing D-glucose $(4.5 \mathrm{~g} / \mathrm{L}), 10 \% \mathrm{FBS}$, and $5 \mathrm{~mm}$ nonessential amino acids. For differentiation of SH-SY5Y cells into a DAergic-like neuronal cell type, $4 \times 10^{5}$ cells were plated per well on a six well plate and differentiated with $10 \mu \mathrm{M}$ retinoic acid in DMEM containing D-glucose $(4.5 \mathrm{~g} / \mathrm{L}), 1 \% \mathrm{FBS}$, and $5 \mathrm{~mm}$ nonessential amino acids. Differentiation was performed for $3 \mathrm{~d}$ before assays or viral infections.

Preparation of cell homogenates. After removal of media, cells were washed once with PBS before lysis in ice-cold radioimmunoprecipitation assay buffer ( $1 \%$ NP-40, $0.1 \%$ deoxycholate, $0.5 \%$ SDS, $50 \mathrm{~mm}$ Tris-Cl, 5 mM EDTA, and $120 \mathrm{~mm} \mathrm{NaCl}$ ), supplemented with Complete miniprotease inhibitor. Samples were then briefly sonicated using a sonic dismembrator (Fisher Scientific), and protein content was quantified using a BCA assay kit.

Western blot analysis. Samples were resolved by SDS-PAGE on $10 \%$ BIS-Tris gels and transferred overnight at $4^{\circ} \mathrm{C}$ onto nitrocellulose membranes. Membranes were blocked in milk solution [5\% milk in Trisbuffered saline with Tween 20 (TBST)] and were then incubated with primary antibodies diluted in TBST with $1 \%$ milk overnight. Following washes in TBST, membranes were incubated with horseradish peroxidase-conjugated secondary antibodies. Immunoreactivity was detected using enhanced chemiluminescence (GE Healthcare) and captured using CL-X Posure X-ray film (Thermo Scientific). Results were quantified using National Institutes of Health ImageJ, version 1.41.

Radiolabeled dopamine release assay. Differentiated SH-SY5Y cells were first infected by the adenovirus expressing the GFP-shLyn, GFPSCR sequence, CA-Lyn, or GFP. Ten days (maximal knockdown of Lyn) or $3 \mathrm{~d}$ (maximal overexpression of CA-Lyn) after virus treatment, culture medium was exchanged for HBSS loading solution ( $135 \mathrm{~mm} \mathrm{NaCl}, 5 \mathrm{~mm}$ $\mathrm{KCl}, 1.3 \mathrm{~mm} \mathrm{Na}_{2} \mathrm{HPO}_{4} \cdot 2 \mathrm{H}_{2} \mathrm{O}, 6 \mathrm{~mm}$ D-glucose, $10 \mathrm{~mm}$ HEPES, $0.2 \mathrm{~mm}$ sodium ascorbate, $0.6 \mathrm{~mm} \mathrm{MgCl}_{2} \cdot 6 \mathrm{H}_{2} \mathrm{O}, 2.5 \mathrm{~mm} \mathrm{CaCl}_{2} \cdot 2 \mathrm{H}_{2} \mathrm{O}$, and $0.1 \% \mathrm{BSA})$. After $2 \times 15$ min washes with loading solution, SH-SY5Y cells were incubated with loading solution containing ${ }^{3} \mathrm{H}-\mathrm{DA}(1 \mu \mathrm{Ci} /$ $\mathrm{ml}$ ). After $30 \mathrm{~min}$ of incubation at $37^{\circ} \mathrm{C}, 5 \% \mathrm{CO}_{2}$, the medium was removed and the cells were washed four times in loading solution (15 min per wash). After washes, the release of ${ }^{3} \mathrm{H}$-DA was evoked by exposing the cells for $2 \mathrm{~min}$ to the loading solution containing $90 \mathrm{~mm} \mathrm{NaCl}$ and $50 \mathrm{~mm} \mathrm{KCl}$ or $40 \mathrm{~mm} \mathrm{NaCl}$ and $100 \mathrm{~mm} \mathrm{KCl}$. Medium was then collected in scintillation vials, and cells were collected and lysed in a 10\% SDS solution. Samples were then mixed with $25 \mathrm{ml}$ of Scintisafe, and radioactivity was measured using the Beckman LS 5000 scintillation counter. The amount of ${ }^{3} \mathrm{H}-\mathrm{DA}$ released into the medium was expressed as a percentage of nontreated SH-SY5Y cells that were only exposed to the loading solution throughout the assay.

Fast-cyclic voltammetry. Coronal NAc slices $(250 \mu \mathrm{m})$ were cut on a Vibratome (VT200, Leica) in ice-cold artificial CSF (aCSF) (126 mM $\mathrm{NaCl}, 2.5 \mathrm{~mm} \mathrm{KCl}, 1.1 \mathrm{~mm} \mathrm{NaH}{ }_{2} \mathrm{PO}_{4}, 1.4 \mathrm{~mm} \mathrm{MgCl}_{2}, 0.5 \mathrm{~mm} \mathrm{CaCl} 2,18$ mм $\mathrm{NaHCO}_{3}, 11 \mathrm{~mm}$ glucose, with $\mathrm{pH} 7.2-7.4$, saturated with $95 \%$ $\mathrm{O}_{2} / 5 \% \mathrm{CO}_{2}$ ). Slices were recovered in a holding chamber for $1 \mathrm{~h}$ at $31^{\circ} \mathrm{C}$ in aCSF containing $1 \mathrm{~mm}$ ascorbic acid. Slices were then placed in the recording chamber and were continuously superfused with an aCSF solution containing $2.4 \mathrm{mM} \mathrm{CaCl}_{2}$ saturated with $95 \% \mathrm{O}_{2}$ and $5 \% \mathrm{CO}_{2}$. Fast-cyclic voltammetry using carbon-fiber microelectrodes $(7 \mu \mathrm{m}$ diameter; $75 \mu \mathrm{m}$ exposed surface; Goodfellow) was used to detect extracellular DA concentration. The scan rate for the fast-cyclic voltammetry was $400 \mathrm{~V} / \mathrm{s}$ with a sampling interval of $100 \mathrm{~ms}$. The scan range was $-0.3-$ $+1.3 \mathrm{~V}$ (vs Ag/AgCl). DA release was evoked by a single stimulation of 0.5 $\mathrm{mA}$ for $0.5 \mathrm{~ms}$ every $5 \mathrm{~min}$. The concentration of the extracellular DA was calculated based on a standard curve $(0.1,1$, and $10 \mu \mathrm{M}$ DA) obtained for each microelectrode at the end of each recording session. 
Lentivirus infection of mice VTA. C57BL/6 mice were anesthetized by systemic administration of a mixture of ketamine $(120 \mathrm{mg} / \mathrm{kg})$ and xylazine $(8 \mathrm{mg} / \mathrm{kg}$ ). Mice were placed in a stereotaxic frame (David Kopf Instruments), and two holes were drilled above the site of viral injection (anteroposterior, $-3.0 \mathrm{~mm}$ from bregma; lateral, $\pm 0.5 \mathrm{~mm}$ from bregma). The injectors (stainless tubing, 33 gauge, Small Parts) were slowly lowered into the VTA (dorsoventral, $-4.7 \mathrm{~mm}$ from bregma). The injectors were connected to Hamilton syringes (10 $\mu \mathrm{l}$; 1701, Harvard Apparatus), and the infusion was controlled by an automatic pump (Harvard Apparatus). Mice received $1.5 \mu \mathrm{l}(0.1 \mu \mathrm{l} / \mathrm{min})$ of virus [LVCA-Lyn or LV-ZsGreen; $1 \times 10^{7}$ infectious units (ifu) $/ \mathrm{ml}$ ] per side. The injectors remained in place for 10 additional minutes to allow the virus to diffuse, and then were slowly removed. Mice were allowed to recover in their home cage, and the experiments started $10 \mathrm{~d}$ after the surgery.

Immunohistochemistry. Brain slices were prepared and stained as previously described (Jeanblanc et al., 2009). Briefly, free-floating sections were permeabilized with $50 \%$ ethanol for $20 \mathrm{~min}$, rinsed in PBS, then blocked with $10 \%$ normal donkey serum in PBS for $30 \mathrm{~min}$, and then incubated for $48 \mathrm{~h}$ at $4^{\circ} \mathrm{C}$ on an orbital shaker with monoclonal anti-TH antibodies (1:2500) in combination with the polyclonal rabbit antiZsGreen antibody (1:1000) diluted in PBS/0.05\% Triton X-100. Sections were then washed three times for 5 min with PBS, and then incubated with $2 \%$ normal donkey serum for $10 \mathrm{~min}$ in the following mixture of secondary antibodies for $3 \mathrm{~h}$ : Alexa Fluor-594 labeled donkey anti-mouse (to detect TH) and Alexa Fluor-488 labeled donkey anti-rabbit (to detect ZsGreen). After staining, sections were washed in PBS, mounted on gelatin-subbed slides, briefly air dried, and coverslipped using Vectashield mounting medium with DAPI (Vector Laboratories). Images were acquired using an LSM 510 META laser confocal microscope with multichannel excitation and detection options using optimal factory recommended filter configurations to minimize spectral bleed-through (Zeiss).

Microdialysis. C57BL/6 mice were microinfused with either LVZsGreen or LV-CA-Lyn in the VTA, and $10 \mathrm{~d}$ later mice were reanesthetized and placed in a stereotaxic frame for the implantation of the guide cannula for the microdialysis probe. Microdialysis guide cannulae (CMA/7, CMA Microdialysis) were inserted stereotaxically (anteroposterior, $+1.0 \mathrm{~mm}$ from bregma; lateral, $+1.0 \mathrm{~mm}$ from bregma; dorsoventral, $-4.0 \mathrm{~mm}$ from the skull surface) and secured to the skull using stainless steel screws and dental cement. The dorsoventral coordinate corresponded to the tip of the guide cannula and the length of the membrane of the microdialysis probe (CMA/7) and $1 \mathrm{~mm}$ below the guide cannula (supplemental Fig. 1, available at www.jneurosci.org as supplemental material). No animals were excluded from the study due to cannula misplacement. After surgery, mice were housed individually and allowed to recover for $4-5 \mathrm{~d}$ before the beginning of the experiment. The evening before the experiment, the microdialysis probes were inserted into the guide cannula, secured with dental cement, and perfused with aCSF (NaCl, $149 \mathrm{~mm}$ KCl, $2.8 \mathrm{~mm} ; \mathrm{CaCl}_{2}, 1.2 \mathrm{~mm} \mathrm{MgCl}_{2}, 1.2 \mathrm{~mm}$; D-glucose, $5.4 \mathrm{~mm}, \mathrm{pH} 7.0$ ) at a rate of $0.3 \mu \mathrm{l} / \mathrm{min}$ overnight. After the period of stabilization, fresh aCSF was perfused at a rate of $0.7 \mu \mathrm{l} / \mathrm{min}$, and sample collection (1 sample every $15 \mathrm{~min}$ ) started $90 \mathrm{~min}$ later. Dialysate DA level was determined using HPLC with electrochemical detection. The chromatographic system consisted of an ESA Analytical model 584 pump, an ESA Analytical microtiter model 540, an ESA Analytical Coulochem III amperometric detector with a model 5011A dualdetector analytical cell (guard cell, $275 \mathrm{mV}$; E1, -150 mV; E2, $220 \mathrm{mV}$ ), and a microbore column $(50 \mathrm{~mm} \times 1.5 \mathrm{~mm} \times 3 \mu \mathrm{m}$; Shizeido $)$. The mobile phase ( $150 \mathrm{~mm} \mathrm{NaH}_{2} \mathrm{PO}_{4}, 4.76 \mathrm{~mm}$ citric acid, $50 \mu \mathrm{M}$ EDTA, $3 \mathrm{~mm}$ SDS, $8 \%$ methanol, $10 \%$ acetonitrile, pH 5.6 adjusted with $\mathrm{NaOH}$ ) was run at a flow rate of $0.2 \mathrm{ml} / \mathrm{min}$. Dialysate DA levels were quantified by external standard curve calibration using area under the curve.

Histology. Mice implanted with microdialysis probes were perfused transcardially with saline $(0.9 \%)$ then with the fixative (4\% paraformaldehyde). Then, $75 \mu \mathrm{m}$ coronal slices were cut and examined for cannulae placement (supplemental Fig. 1, available at www.jneurosci.org as supplemental material).

Conditioned place preference. The rewarding effect of ethanol was determined using the conditioned place preference $(\mathrm{CPP})$ procedure. The testing apparatus (Med Associates) consisted of two compartments
$(16.8 \times 12.7 \mathrm{~cm}$ each) with distinct visual and tactile cues (conditioning compartments). One compartment has white walls and a stainless steel mesh floor, and the other compartment has black walls and a floor consisting of stainless steel rods placed every $8 \mathrm{~mm}$ (center to center). A small center compartment $(2.8 \times 12.7 \mathrm{~cm})$ with gray walls and a solid plastic floor separates the two other compartments. The center compartment is equipped with computer-controlled guillotine doors that provide access to one or both of the conditioning compartments. On the first day of the experiment (habituation session), mice had free access to the three different compartments for a period of $30 \mathrm{~min}$. Mice that spent $>70 \%$ of the time in either one of the compartments during the habituation session were excluded from the study (Lyn KO, $n=2$; Lyn WT, $n=1$, LtvCALyn, $n=1$ ). An unbiased design (unbiased apparatus and unbiased assignment procedure) was used (Tzschentke, 2007). In the morning of the first day of conditioning (the day following habituation), mice received an intraperitoneal injection of either saline or ethanol $(2 \mathrm{~g} / \mathrm{kg}$, $20 \% \mathrm{v} / \mathrm{v}$ solution) (Tzschentke, 2007). Immediately after the treatment, mice were placed within either the white or the black compartment for 5 min. Six hours later, mice received an intraperitoneal injection of the solution they had not previously received. Mice were then immediately placed for 5 min within the compartment they did not experience during the first session. As a control, a group of mice received saline injections before each conditioning session. The conditioning phase lasted for $3 \mathrm{~d}$ for the experiment using the transgenic mice, and $5 \mathrm{~d}$ for the experiment using mice in which the VTA was infected with a virus. On the test day (the day following the last day of conditioning), mice were allowed to move across the three compartments for $30 \mathrm{~min}$. The time spent in each conditioned compartment was recorded by photo beams placed $1.2 \mathrm{~cm}$ apart in the conditioning compartments. Results are expressed as a preference ratio \pm SEM. The preference ratio was calculated as the time spent in the ethanol-paired compartment divided by the time spent in the saline-paired compartment during the preconditioning or test session.

Statistical analysis. CPP data were analyzed by a three-way mixed model $2 \times 2 \times 2$ ANOVA with a within-subject factor of conditioning (preconditioning, postconditioning), and a between-subjects factor of ethanol treatment (saline, ethanol) and genotype (WT, KO) or virus pretreatment (control, CA-Lyn), followed by post hoc analyses. Microdialysis data were analyzed by a two-way mixed model ANOVA with a between-subjects factor of virus pretreatment (control, CA-Lyn) and a repeated measurements factor of fractions. Otherwise, data were analyzed as indicated, by Student's $t$ test or by one- or two-way ANOVA with or without repeated measures, followed by post hoc analysis (NewmanKeuls test) when indicated. Data are expressed as the mean \pm SEM. Since the voltammetric data (of the area under the curve) failed to fulfill the assumptions of parametric statistical tests, the data were analyzed using a nonparametric test (Mann-Whitney).

\section{Results}

\section{Lyn negatively regulates dopamine release}

To test the possible contribution of Lyn kinase in the regulation of DA exocytosis, we used the neuroblastoma cell line SH-SY5Y and measured calcium-dependent DA release after altering the level and activity of Lyn. SH-SY5Y cells can be differentiated into a DAergic-like cell type (Påhlman et al., 1984) and are therefore used to study DAergic neurotransmission (Ault and Werling, 2000). Specifically, differentiated SH-SY5Y express voltage-gated $\mathrm{Ca}^{2+}$ channels, which can be activated by increasing extracellular potassium to induce depolarization resulting in neurotransmitter release (Murphy et al., 1991). First, we confirmed that the incubation of differentiated SH-SY5Y cells with pan-Src PTKs inhibitor PP2 results in an increase in $\mathrm{KCl}$-mediated DA release (Fig. 1a) $\left(t_{(4)}=3.99 ; p<0.02\right)$. Next, to test the effect of the reduction of Lyn levels on the release of DA, we created an adenovirus expressing an shRNA sequence targeting Lyn (AdvshLyn), and maximal knockdown of protein level was observed $10 \mathrm{~d}$ after infection (Fig. 1b,c) [two-way ANOVA: main effects of virus treatment $\left(F_{(2,12)}=22.59, p<0.0001\right)$ and time points 


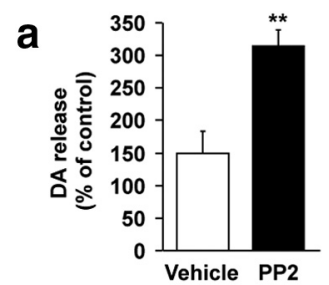

b
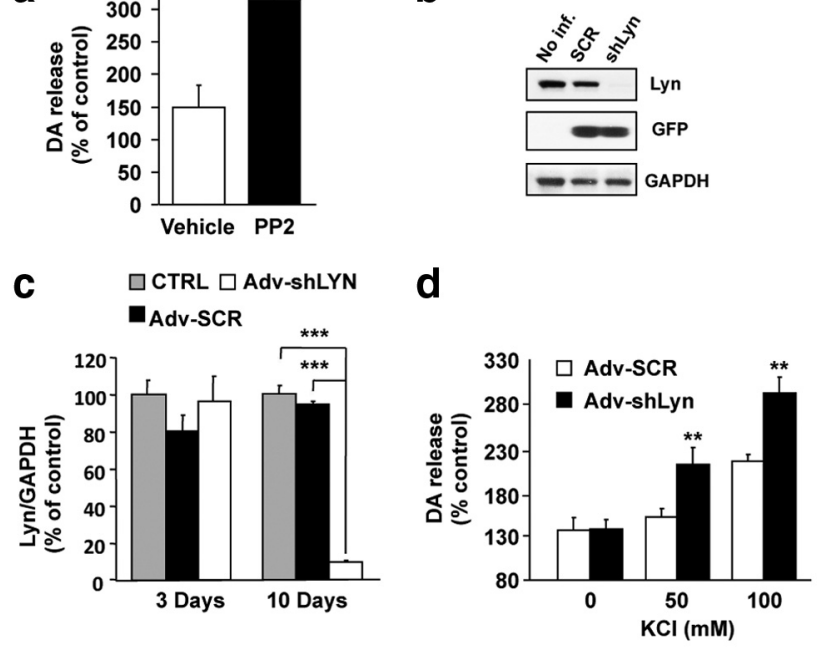

e
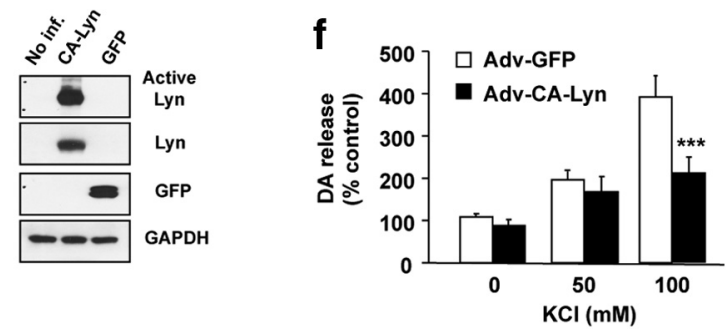

Figure 1. Alterations in the level and activity of Lyn result in modulation of DA release in differentiated SH-SY5Y cells. $\boldsymbol{a},{ }^{3} \mathrm{H}$-DA release assay. SH-SY5Y cells were preincubated for 30 min with the pan-Src PTKs inhibitor PP2 (50 $\mu \mathrm{M})$. Cells were depolarized with KCI (100 mM). After 2 min of depolarization, media and cell lysates were separately collected. Data were analyzed as a percentage of DA release and expressed as the mean \pm SEM percentage of non-depolarized controls $(n=3)$. ${ }^{* *} p<0.01$. $\boldsymbol{b}$, Infection of SH-SY5Y cells with either the Adv-shLyn or the scrambled sequence control (Adv-SCR). Viruses were used at a concentration of $1 \times 10^{7} \mathrm{ifu} / \mathrm{ml}$ (predetermined maximal effective concentration, data not shown). Protein lysates were collected after $10 \mathrm{~d}$ of infection and Lyn levels were analyzed by Western blot with anti-Lyn antibodies (1:500). Anti-GFP antibodies were used as a method of detecting virus infection, and GAPDH levels were measured to verify equal sample loading ( $n=3)$. c, Time course for knockdown of Lyn protein levels in SH-SY5Y cells infected with either Adv-shLyn or Adv-SCR. As in $\boldsymbol{b}$, viruses were used at a concentration of $1 \times 10^{7} \mathrm{ifu} / \mathrm{ml}$. Lyn levels were analyzed by Western blot as in $\boldsymbol{b}$. Data are expressed as a percentage of the ratio of Lyn/GAPDH in the control samples $(n=3) .{ }^{* * *} p<0.001 . \boldsymbol{d},{ }^{3} \mathrm{H}-\mathrm{DA}$ release assay. SH-SY5Y cells were depolarized with $\mathrm{KCl}(50 \mathrm{~mm}, 100 \mathrm{~mm})$. After $2 \mathrm{~min}$ of depolarization, media and cell lysates were separately collected. Data were analyzed as the percentage of DA release and expressed as the mean \pm SEM percentage of uninfected controls $(n=3) .{ }^{* *} p<0.01$. Results are expressed as the mean \pm SEM percentage of non-depolarized controls $(n=3) .{ }^{* *} p<0.01$. $\boldsymbol{e}$, Infection of SH-SY5Y cells with an adenovirus expressing constitutively active Lyn (Adv-CA-Lyn) or control (Adv-GFP). Active Lyn levels were analyzed by Western blot with a pan-active Src PTKs antibody anti-[pY $\left.{ }^{418}\right]$ Src. Total Lyn levels were detected using anti-Lyn antibodies; anti-GFP antibodies were used to detect the control virus, and GAPDH levels were measured to verify equal sample loading $(n=3) . f^{3}{ }^{3} \mathrm{H}-\mathrm{DA}$ release assay. Cells were infected for $3 \mathrm{~d}$ with Adv-CA-Lyn or Adv-GFP, cells were depolarized, and data were analyzed as in $\boldsymbol{d}$. The results are expressed as the mean \pm SEM percentage of uninfected controls $(n=3) .{ }^{* *} p<0.001$.

$\left(F_{(1,12)}=16.62, p<0.02\right)$, as well as a significant interaction between the two factors $\left.\left(F_{(2,12)}=28.11, p<0.0001\right)\right]$; post hoc analyses show a significant difference on day 10 between shLyn and control as well as SCR ( $p$ values $<0.0001$ ), but no difference between control and SCR on that day, and no differences among the three groups on day 3. As shown in Figure $1 d$, treatment of control cells with $\mathrm{KCl}$ resulted in increased DA release; however, knockdown of Lyn induced a much greater increase in DA release compared with cells infected with the adenovirus expressing the scrambled sequence (Adv-SCR). A two-way ANOVA revealed a

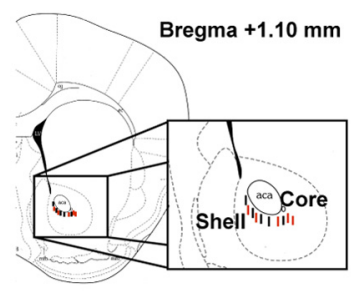

b
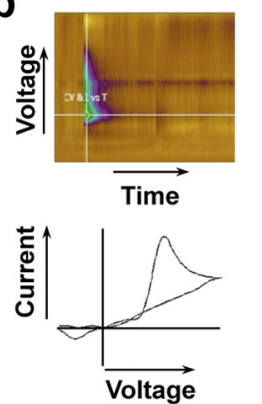

d
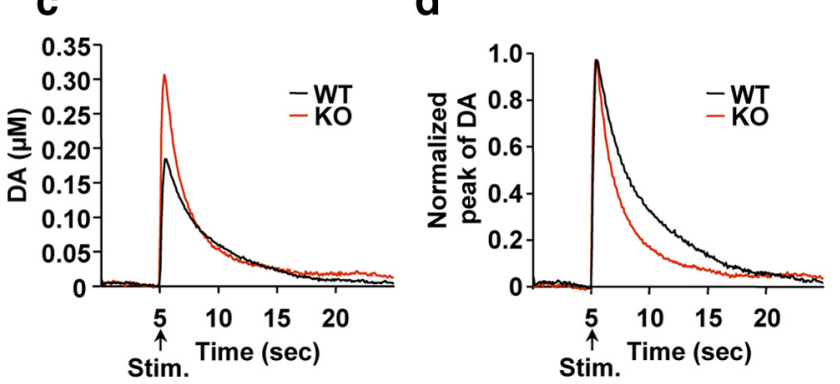

Figure 2. Lyn KO mice have a higher level of extracellular DA in the NAc than WT mice. $\boldsymbol{a}$, Placement of the recording microelectrode in the core of the NAc of WT (black line) and KO (red lines) mice [diagram adapted from Paxinos and Franklin (2001)]. b, Voltammogram and curve fit representatives of electrically evoked DA changes measured in the core of the NAc slices. $\boldsymbol{c}$, Stimulation was produced by a double-stimulating electrode system placed $100 \mu \mathrm{m}$ below the recording electrode. The duration of the stimulation was $0.5 \mathrm{~ms}$, and the amplitude was $0.5 \mathrm{~mA}$. Results are expressed as the mean DA concentration $(\mu \mathrm{M})$. WT and $\mathrm{K} 0, n=5$, Mann-Whitney test, $p<0.001$. $\boldsymbol{d}$, Results are expressed as the mean of normalized peaks of DA. WT and KO, $n=5$. Mann-Whitney test, $p<0.001$.

the main effects of the factors virus $\left(F_{(1,21)}=15.15 ; p<0.001\right)$ and treatment $\left(F_{(2,21)}=32.26 ; p<0.001\right)$, and an interaction between both factors $\left(F_{(2,21)}=3.9 ; p<0.05\right)$. Post hoc analyses found a significant difference between the Adv-shLyn- and AdvSCR-treated cells for both concentrations of $\mathrm{KCl}$ ( $p$ values $<0.01$ ). If the reduction in protein levels (and therefore activity) of Lyn leads to an elevation in DA release, then increasing expression and activity of the kinase should have an opposite effect. To test this possibility, we created an adenovirus that overexpresses a constitutively active form of Lyn (Adv-CA-Lyn) (Fig. 1e) and observed that increased expression and activity of Lyn resulted in a reduction of $\mathrm{KCl}$-induced $\mathrm{DA}$ release compared with the control virus expressing GFP (Adv-GFP) (Fig. 1f). A two-way ANOVA found main effects of virus $\left(F_{(1,20)}=9.44 ; p<0.01\right)$ and treatment $\left(F_{(2,20)}=22.88 ; p<0.001\right)$, and an interaction between both factors $\left(F_{(2,20)}=4.42 ; p<0.05\right)$ post hoc analyses revealed a significant difference between Adv-GFP and the AdvCA-Lyn-infected cells treated with $100 \mathrm{~mm} \mathrm{KCl}(p<0.001))$. Together, these results suggest that Lyn negatively regulates the evoked release of DA.

Next, to examine whether Lyn plays a role in the negative regulation of DA release in the mesolimbic system (e.g., the DAergic neurons that originate from the VTA and project to the NAc), we used fast-cyclic voltammetry recording and compared the profile of DA overflow in NAc slices of Lyn KO mice and WT littermate controls. Since in Lyn KO mice the Lyn gene is absent during development and throughout adulthood (Hibbs et al., 1995), we first verified that the deletion of the gene does not result in compensatory changes in the protein level of other Src PTK members, Fyn and Src. As expected, Lyn is expressed in the brain 
of Lyn WT but not Lyn KO mice, and the levels of Fyn and Src do not differ between the two genotypes (supplemental Fig. $2 a$, available at www.jneurosci.org as supplemental material). Carbon fiber electrodes were placed in the core of the NAc, as shown in Figure $2 a$; the release of DA was induced by the application of electrical stimulation $100 \mu \mathrm{m}$ ventral to the recording electrode, and the DA signal was identified on the voltammogram (Fig. 2b). We observed that the evoked release of DA was higher in Lyn $\mathrm{KO}$ mice compared with the WT mice (Fig. 2c). A MannWhitney test conducted on the area under the curve revealed a significant difference between the genotypes ( $U=16310, p<$ $0.001)$. The higher levels of DA observed in the NAc of Lyn KO mice could be due to a lower level of DA reuptake through the DA transporter. However, by normalizing the peaks of DA obtained after stimulation (Fig. $2 d$ ), we observed that the area under the curve was significantly smaller for Lyn $\mathrm{KO}$ mice compared with the WT mice (MannWhitney $U$ test $=15140, p<0.0001$ ), suggesting that the reuptake of DA is faster in the NAc of Lyn KO mice compared with the NAc of WT mice. Thus, the higher level of extracellular DA in the NAc of Lyn KO mice after stimulation is due to an increased release of DA from the presynaptic terminals.

\section{Lyn controls ethanol-mediated DA} release and reward

Previous studies showed that systemic, intravenous administration of nonsedative moderate doses of ethanol, as well as ethanol self-administration, results in a rapid increase in DA release within the mesolimbic system (Gonzales et al., 2004). Therefore, we tested the hypothesis that Lyn negatively regulates ethanol-mediated DA release, and, by doing so, the kinase controls the rewarding properties of ethanol. First, to determine whether alteration in Lyn activity changes the level of extracellular DA in response to ethanol, we used microdialysis and tested whether overexpression of CA-Lyn in VTA DAergic neurons of C57BL/6 mice affects ethanol-induced DA release in the NAc. To do so, we created a lentivirus expressing CA-Lyn (LV-CALyn) and a control lentivirus expressing Zs Green (LV-ZsGreen). As shown in Figure 3a, LV-CA-Lyn infection was localized to the VTA, and resulted in the overexpression of the active kinase (Fig. 3b). As shown in Figure $3 c$, there was no difference between the LV-ZsGreen and LV-CA-Lyn groups before ethanol treatment (mixed-model two-way ANOVA, no significant main effects, or virus pretreatment $\times$ fraction interaction before ethanol treatment); however, systemic administration of $2 \mathrm{~g} / \mathrm{kg}$ ethanol led to a rapid increase in DA release in the NAc in the LV-ZsGreen group; however, no change in DA level was observed in the LV-CA-Lyn group after ethanol treatment [mixed-model two-way ANOVA; main effect of virus pretreament $\left.\left(F_{(1,18)}=7.08, p<0.05\right)\right]$. These results suggest that increased activity of Lyn in the VTA is directly associated with the inhibition of ethanol-mediated DA release. b
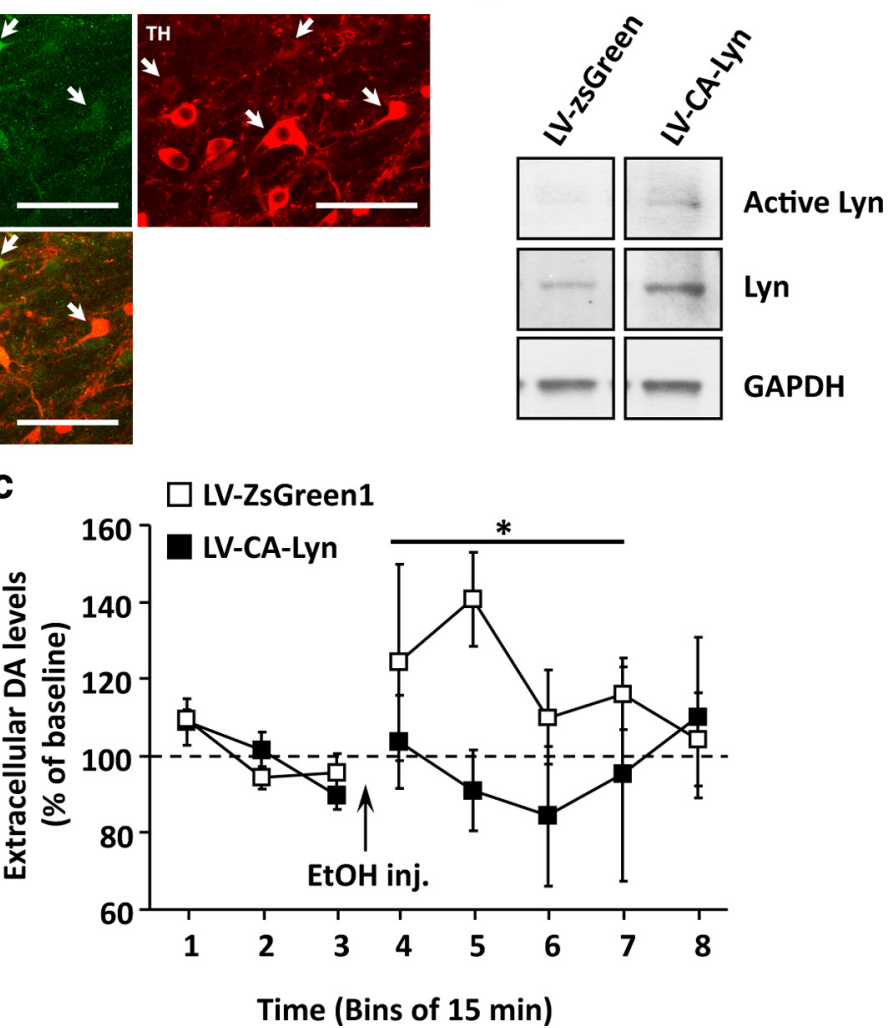

Time (Bins of $15 \mathrm{~min}$ )

Figure 3. Overexpression of CA-Lyn in the mesolimbic system blocks ethanol-induced increase of DA in the NAc. Mice were

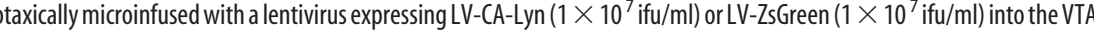
a the day of the experiment, mice received a systemic administration of ethanol $(2 \mathrm{~g} / \mathrm{kg})$. The basal levels of DA were $0.74 \pm 0.10 \mathrm{~nm}$ for the LV-ZsGreen mice and $1.10 \pm 0.38 \mathrm{~nm}$ for the LV-CA-Lyn mice. The results are expressed as the mean \pm SEM of extracellular DA (percentage of baseline). LV-ZsGreen and LV-CA-Lyn, $n=4 .{ }^{*} p<0.05$.

Next, we hypothesized that the modulation of DA release by Lyn leads to changes in the rewarding properties of ethanol. The CPP procedure is widely used to examine the rewarding and reinforcing actions of drugs (Tzschentke, 2007). We therefore used this assay to test whether alteration in the level and activity of Lyn alters ethanol reward. First, the VTA of C57BL/6 mice were infected with LV-CA-Lyn or LV-ZsGreen, and the levels of ethanol place preference were measured $10 \mathrm{~d}$ later. We found that both groups of mice did not show any preference for a specific compartment of the CPP chambers during the preconditioning period (Fig. 4). In addition, on test day saline-treated mice showed no place preference regardless of the virus pretreatment. However, among ethanol-conditioned mice, CPP to the ethanolpaired compartment was observed in the control mice expressing LV-ZsGreen in the VTA but was not detected in the mice expressing LV-CA-Lyn in the VTA (Fig. 4) [mixed-model three-way ANOVA, significant interactions of virus pretreatment $X$ ethanol treatment $\left(F_{(1,30)}=6.15, p<0.02\right)$ and conditioning $\times$ virus pretreatment $\left(F_{(1,30)}=4.21, p<0.05\right)$; post hoc analyses: $p<0.01$ for LV-ZsGreen, and $p=0.36$ for LV-CA-Lyn]. These results indicated that the activation of Lyn in the VTA blocks ethanol reward.

Finally, to test whether the absence of the Lyn gene results in an opposite phenotype (e.g., in a higher degree of ethanol place preference), we compared the level of CPP to ethanol in Lyn KO 


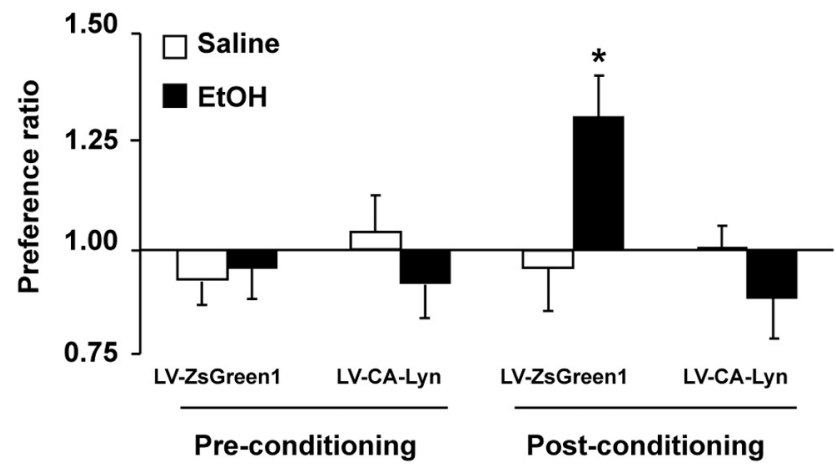

Figure 4. Overexpression of CA-Lyn in the VTA blocks ethanol place preference. Mice were stereotaxically microinfused with LV-CA-Lyn $\left(1 \times 10^{7} \mathrm{ifu} / \mathrm{ml}\right)$ or LV-ZsGreen $\left(1 \times 10^{7} \mathrm{ifu} / \mathrm{ml}\right)$ in the VTA. Ten days after the microinfusion, mice were subjected to the CPP protocol with $5 \mathrm{~d}$ of conditioning. During the test day, animals were given free access to both contexts for $30 \mathrm{~min}$, and the amount of time spent in the ethanol- and saline-paired compartments was measured. Results are expressed as the mean \pm SEM of preference ratio (time spent in ethanol-paired compartment/time spent in saline-paired compartment). LV-ZsGreen Saline, $n=7$; LV-CA-Lyn saline, $n=7$; LV-ZsGreen EtOH, $n=10$; LV-CA-Lyn EtOH, $n=10 .{ }^{*} p<0.01$.

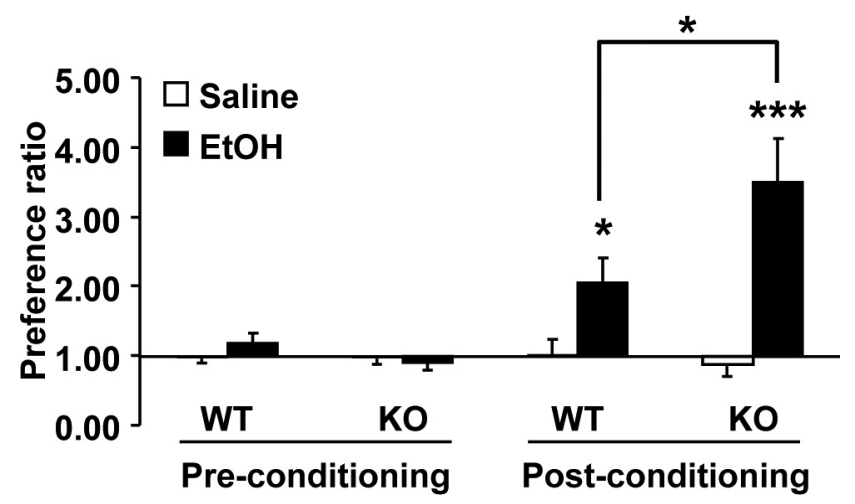

Figure 5. Lyn deletion increases ethanol place preference. Lyn KO and WT mice received daily systemic administration of saline or ethanol $(2 \mathrm{~g} / \mathrm{kg})$ during conditioning. On test day, animals were given free access to both contexts for $30 \mathrm{~min}$, and the amount of time spent in the ethanol- and saline-paired compartments was measured. A CPP score was calculated by subtracting the time spent in the saline-paired context to the time spent in the ethanol-paired context. Results are expressed as the mean \pm SEM of preference ratio (time spent in ethanolpaired compartment/time spent in saline-paired compartment). $\mathrm{KO}$ saline, $n=8$; WT saline, $n=10 ; \mathrm{KOEtOH}, n=11$; WT EtOH, $n=12 .{ }^{*} p<0.05,{ }^{* * *} p<0.0001$.

and WT mice. As shown in Figure 5, neither Lyn KO nor WT mice showed a preference for either side of the CPP chambers during the preconditioning sessions or after systemic administration of saline. However, after the conditioning to ethanol, Lyn KO mice exhibited a significantly higher preference for the ethanol-paired compartment compared with the WT mice. This was confirmed by a mixed-model three-way ANOVA, which yielded significant main effects of conditioning $\left(F_{(1,37)}=14.07\right.$; $p<0.001)$ and ethanol treatment $\left(F_{(1,37)}=18.02 ; p<0.0001\right)$, as well as significant interactions of conditioning $X$ ethanol treatment $\left(F_{(1,37)}=18.47 ; p<0.0001\right)$ and conditioning $\times$ ethanol treatment $\times$ genotype $\left(F_{(1,37)}=4.93 ; p<0.05\right)$. Post hoc analysis revealed a significant difference between ethanol- and salinetreated mice in Lyn WT $(p<0.05)$ and Lyn KO $(p<0.0001)$ mice, as well as between WT and KO mice treated with ethanol $(p<0.05)$. The increase in ethanol place preference was not due to differences in locomotor activity between the genotypes (supplemental Fig. $2 b$, available at www.jneurosci.org as supplemental material), and there was no difference between the genotypes in the duration of ethanol-mediated loss of righting reflex (supplemental Fig. $2 c$, available at www.jneurosci.org as supplemental material). A two-way mixed-model ANOVA revealed a main effect of the within-subject factor treatment $\left(F_{(2,16)}=12.24 ; p<\right.$ $0.001)$, but no effect of genotype $\left(F_{(1,16)}=0.03\right.$; ns $)$ and no interaction between these two factors $\left(F_{(2,16)}=1.09 ; n s\right)$. Finally, Lyn KO and Lyn WT mice exhibited a similar rate of ethanol metabolism (supplemental Fig. 2d, available at www.jneurosci.org as supplemental material). A two-way mixed-model ANOVA revealed a main effect of time $\left(F_{(2,18)}=8.79 ; p<0.01\right)$, but no effect of genotype $\left(F_{(1,18)}=1.77 ; \mathrm{ns}\right)$ and no interaction between both factors $\left(F_{(2,18)}=0.43 ; \mathrm{ns}\right)$. Together, these results suggest that Lyn negatively regulates the rewarding properties of ethanol.

\section{Discussion}

Our results suggest a novel role for Lyn kinase in the mesocorticolimbic DAergic system as a negative regulator of DA release. Specifically, we show that knockdown of the Lyn gene in differentiated SH-SY5Y cells increases DA release, whereas overexpression of the active form of the kinase attenuates DA release. In addition, we observed that the evoked release of DA is higher in the NAc of Lyn KO mice when compared with the WT littermates. We further show that ethanol-mediated DA release and reward are affected by the alterations in the level and activity of Lyn kinase. Specifically, ethanol-induced increase in DA release in the NAc and ethanol reward were abolished upon infection of VTA neurons with the active form of the kinase. Finally, the level of ethanol place preference was elevated in the absence of the kinase. Together, our results suggest that Lyn plays a unique role in the regulation of DA release in the mesolimbic system, and by doing so, the kinase contributes to controlling the degree of ethanol reward.

Possible mechanisms underlying Lyn-mediated regulation of DA release

We show that DA release induced by depolarization of the $\mathrm{SH}$ SY5Y cells is altered by the knockdown of Lyn or the overexpression of CA-Lyn. However, the baseline level of DA release was not affected by the modifications of Lyn activity. Moreover, Lyn KO mice or mice overexpressing CA-Lyn do not show differences in baseline levels of DA release, compared with their respective controls. However, upon electrical stimulation or ethanol administration, the release of DA was altered in both Lyn KO mice and in the mice overexpressing CA-Lyn compared with their controls. Together, these results suggest that phasic but not tonic release of DA is altered by Lyn activity.

The molecular mechanism by which Lyn negatively regulates DA exocytosis in the mesocorticolimbic system is currently unknown. However, the data obtained upon electrical stimulation of DA release in NAc slice preparations from Lyn WT and KO mice suggest, at least in part, a presynaptic mechanism as the synaptic terminals have been disconnected from their cell bodies. It is highly likely that Lyn-mediated inhibition of DA release involves kinase activity and phosphorylation of substrates. Interestingly, Src PTKs have been reported to negatively regulate both calcium-mediated release of neurotransmitter (Ohnishi et al., 2001) and insulin (Cheng et al., 2007), and our results suggest that the Src PTK Lyn is the kinase responsible for this inhibitory action. Src-PTKs have been reported to phosphorylate the synaptic vesicle-associated proteins synaptophysin (Evans and Cousin, 2005) and synapsin I (Onofri et al., 2007). Onofri et al. (2007) demonstrated that phosphorylation of synapsin is inversely proportional to neurotransmitter release in cortical syn- 
aptosomes, and this observation is in agreement with our findings showing that Lyn activity is inversely proportional to neurotransmitter release using a dopaminergic-like cell-based assay. Although this phenomenon of phosphorylation of synaptic vesicle proteins is intriguing, the above-mentioned studies relate to the entire family of Src-PTKs, and therefore the relevance to the function of Lyn in DA release merits further investigation. Interestingly, a recent study showed that Lyn phosphorylates the $\mathrm{SH} 2$-containing tyrosine phosphatase (SHP-1), resulting in the inhibition of the phosphatase (Xiao et al., 2010). SHP-1 was reported to be associated with synaptic vesicles and to interact with synaptophysin (Jena et al., 1997). Together, these results raise the possibility that Lyn-mediated reduction of SHP-1 activity may contribute to the inhibitory actions of the kinase on synaptic release of DA.

Rearrangement of the actin cytoskeleton is another mechanism that warrants consideration. Indeed, the densification of the actin cytoskeleton is a possible mechanism of regulation of exocytosis (Noda and Sasaki, 2008). In pancreatic cells, which express only Yes and Lyn, Lynch et al. (2004) demonstrated that Yes (but without excluding Lyn) is responsible for the densification of the actin cytoskeleton at the apical pole of the cell and that this densification blocks the exocytosis of amylase. In the neuronal cell model of PC12 cells, Ohnishi et al. (2001) observed that inhibition of the Src-PTKs using PP2 resulted in a reduction in filopodia extensions and a decrease in phalloidin staining, a marker of fibrillar actin. Furthermore, inhibition of actin polymerization also caused an enhancement in calcium-dependent release in PC12 cells (Ohnishi et al., 2001). Thus, if Lyn phosphorylates either or both synaptic vesicle proteins and components of the actin cytoskeleton, exocytosis may be reduced.

\section{Lyn contributes to the negative regulation of ethanol- mediated DA release and reward}

Various studies show that voluntary and nonvoluntary exposure of rodents to ethanol results in a rapid increase in DA release in the NAc (Gonzales et al., 2004). The peak of extracellular DA reaches a maximum level (15-70\% above baseline) within $30 \mathrm{~min}$ and then rapidly decreases (Imperato and Di Chiara, 1986; Howard et al., 2008; Robinson et al., 2009), and we obtained a similar profile after systemic administration of a moderate dose $(2 \mathrm{~g} / \mathrm{kg})$ of ethanol. Importantly, we show that overexpression of the active form of Lyn in the VTA blocked ethanol-mediated DA release. Src PTKs play a role in the regulation of the glutamatergic signaling (Salter and Kalia, 2004). Therefore, although our data strongly suggest that the mesolimbic DAergic signaling is controlled by Lyn, we cannot exclude the possibility that glutamatergic signaling may also be altered after manipulations of the levels and/or activity of the kinase.

We also observed that place preference for ethanol (i.e., the rewarding properties of the drug) is increased in Lyn $\mathrm{KO}$ mice compared with WT mice, and conversely is decreased in mice overexpressing CA-Lyn in VTA neurons compared with control mice. DA transmission is a contributor to ethanol reward-related behaviors (Gonzales et al., 2004), and we show that there is an inverse correlation between the level and the activity of the kinase and the rewarding properties of ethanol. Our results put forward the possibility that Lyn contributes to a protective mechanism against an aberrant release of DA, and by acting as a break to prevent further DA release the kinase may play a role in the reduction of ethanol-related behaviors. This possibility is in line with previous studies by us and others suggesting that endogenous regulatory mechanisms control the adverse actions of etha- nol (McGough et al., 2004; Pandey et al., 2006; Carnicella and Ron, 2009; Jeanblanc et al., 2009). However, although our results suggest that Lyn modulates DA release to control ethanol reward, other mechanisms are plausible either in concert or in part, and therefore additional experiments are necessary to add further insight.

\section{Other possible implications}

Our study focused on the modulation of DA release by Lyn and the resulting controlling of the rewarding properties of ethanol. However, our findings could also be relevant to the regulation of the rewarding properties of natural rewards, as well as other drugs of abuse. The results may also have implications for other processes that are linked to the mesolimbic DA system such as incentive salience (Berridge and Robinson, 1998; Fields et al., 2007) and stress (Ungless et al., 2010).

\section{References}

Ault DT, Werling LL (2000) SH-SY5Y cells as a model for sigma receptor regulation of potassium-stimulated dopamine release. Brain Res 877:354-360.

Berridge KC, Robinson TE (1998) What is the role of dopamine in reward: hedonic impact, reward learning, or incentive salience? Brain Res Brain Res Rev 28:309-369.

Carnicella S, Ron D (2009) GDNF- a potential target to treat addiction. Pharmacol Ther 122:9-18.

Chen C, Leonard JP (1996) Protein tyrosine kinase-mediated potentiation of currents from cloned NMDA receptors. J Neurochem 67:194-200.

Cheng H, Straub SG, Sharp GW (2007) Inhibitory role of Src family tyrosine kinases on $\mathrm{Ca} 2+$-dependent insulin release. Am J Physiol Endocrinol Metab 292:E845-E852.

Evans GJ, Cousin MA (2005) Tyrosine phosphorylation of synaptophysin in synaptic vesicle recycling. Biochem Soc Trans 33:1350-1353.

Fields HL, Hjelmstad GO, Margolis EB, Nicola SM (2007) Ventral tegmental area neurons in learned appetitive behavior and positive reinforcement. Annu Rev Neurosci 30:289-316.

Gonzales RA, Job MO, Doyon WM (2004) The role of mesolimbic dopamine in the development and maintenance of ethanol reinforcement. Pharmacol Ther 103:121-146.

Grace AA (2008) Physiology of the normal and dopamine-depleted basal ganglia: insights into levodopa pharmacotherapy. Mov Disord 23 [Suppl 3]:S560-S569.

Harder KW, Parsons LM, Armes J, Evans N, Kountouri N, Clark R, Quilici C, Grail D, Hodgson GS, Dunn AR, Hibbs ML (2001) Gain- and loss-offunction Lyn mutant mice define a critical inhibitory role for Lyn in the myeloid lineage. Immunity 15:603-615.

Hayashi T, Huganir RL (2004) Tyrosine phosphorylation and regulation of the AMPA receptor by SRC family tyrosine kinases. J Neurosci 24:6152-6160.

Hayashi T, Umemori H, Mishina M, Yamamoto T (1999) The AMPA receptor interacts with and signals through the protein tyrosine kinase Lyn. Nature 397:72-76.

Hernandez-Hansen V, Mackay GA, Lowell CA, Wilson BS, Oliver JM (2004) The Src kinase Lyn is a negative regulator of mast cell proliferation. J Leukoc Biol 75:143-151.

Hibbs ML, Stanley E, Maglitto R, Dunn AR (1995) Identification of a duplication of the mouse Lyn gene. Gene 156:175-181.

Howard EC, Schier CJ, Wetzel JS, Duvauchelle CL, Gonzales RA (2008) The shell of the nucleus accumbens has a higher dopamine response compared with the core after non-contingent intravenous ethanol administration. Neuroscience 154:1042-1053.

Hyman SE, Malenka RC, Nestler EJ (2006) Neural mechanisms of addiction: the role of reward-related learning and memory. Annu Rev Neurosci 29:565-598.

Imperato A, Di Chiara G (1986) Preferential stimulation of dopamine release in the nucleus accumbens of freely moving rats by ethanol. J Pharmacol Exp Ther 239:219-228.

Jeanblanc J, He DY, Carnicella S, Kharazia V, Janak PH, Ron D (2009) Endogenous BDNF in the dorsolateral striatum gates alcohol drinking. J Neurosci 29:13494-13502. 
Jena BP, Webster P, Geibel JP, Van den Pol AN, Sritharan KC (1997) Localization of SH-PTP1 to synaptic vesicles: a possible role in neurotransmission. Cell Biol Int 21:469-476.

Lynch G, Kohler S, Leser J, Beil M, Garcia-Marin LJ, Lutz MP (2004) The tyrosine kinase Yes regulates actin structure and secretion during pancreatic acinar cell damage in rats. Pflugers Arch 447:445-451.

McGough NN, He DY, Logrip ML, Jeanblanc J, Phamluong K, Luong K, Kharazia V, Janak PH, Ron D (2004) RACK1 and brain-derived neurotrophic factor: a homeostatic pathway that regulates alcohol addiction. J Neurosci 24:10542-10552.

Metere A, Mallozzi C, Minetti M, Domenici MR, Pèzzola A, Popoli P, Di Stasi AM (2006) Quinolinic acid modulates the activity of src family kinases in rat striatum: in vivo and in vitro studies. J Neurochem 97:1327-1336.

Murphy NP, Ball SG, Vaughan PF (1991) Potassium- and carbachol-evoked release of $[3 \mathrm{H}]$ noradrenaline from human neuroblastoma cells, SHSY5Y. J Neurochem 56:1810-1815.

Noda Y, Sasaki S (2008) The role of actin remodeling in the trafficking of intracellular vesicles, transporters, and channels: focusing on aquaporin-2. Pflugers Arch 456:737-745.

Ohnishi H, Yamamori S, Ono K, Aoyagi K, Kondo S, Takahashi M (2001) A src family tyrosine kinase inhibits neurotransmitter release from neuronal cells. Proc Natl Acad Sci U S A 98:10930-10935.

Onofri F, Messa M, Matafora V, Bonanno G, Corradi A, Bachi A, Valtorta F, Benfenati F (2007) Synapsin phosphorylation by SRC tyrosine kinase enhances SRC activity in synaptic vesicles. J Biol Chem 282:15754-15767.

Påhlman S, Ruusala AI, Abrahamsson L, Mattsson ME, Esscher T (1984) Retinoic acid-induced differentiation of cultured human neuroblastoma cells: a comparison with phorbolester-induced differentiation. Cell Differ 14:135-144.

Palacios EH, Weiss A (2004) Function of the Src-family kinases, Lck and Fyn, in T-cell development and activation. Oncogene 23:7990-8000.

Pandey SC, Zhang H, Roy A, Misra K (2006) Central and medial amygdaloid brain-derived neurotrophic factor signaling plays a critical role in alcohol-drinking and anxiety-like behaviors. J Neurosci 26:8320-8331.

Paxinos G, Franklin KBJ (2001) The mouse brain in stereotaxic coordinates, Ed 2. New York: Academic.

Pereira S, Lowell C (2003) The Lyn tyrosine kinase negatively regulates neutrophil integrin signaling. J Immunol 171:1319-1327.

Ptasznik A, Nakata Y, Kalota A, Emerson SG, Gewirtz AM (2004) Short interfering RNA (siRNA) targeting the Lyn kinase induces apoptosis in primary, and drug-resistant, BCR-ABL1 $(+)$ leukemia cells. Nat Med 10:1187-1189.

Robinson DL, Howard EC, McConnell S, Gonzales RA, Wightman RM (2009) Disparity between tonic and phasic ethanol-induced dopamine increases in the nucleus accumbens of rats. Alcohol Clin Exp Res 33:1187-1196.

Salter MW, Kalia LV (2004) Src kinases: a hub for NMDA receptor regulation. Nat Rev Neurosci 5:317-328.

Scapini P, Pereira S, Zhang H, Lowell CA (2009) Multiple roles of Lyn kinase in myeloid cell signaling and function. Immunol Rev 228:23-40.

Schultz W (2007) Multiple dopamine functions at different time courses. Annu Rev Neurosci 30:259-288.

Tiscornia G, Singer O, Verma IM (2006) Production and purification of lentiviral vectors. Nat Protoc 1:241-245.

Tzschentke TM (2007) Measuring reward with the conditioned place preference (CPP) paradigm: update of the last decade. Addict Biol $12: 227-462$.

Umemori H, Wanaka A, Kato H, Takeuchi M, Tohyama M, Yamamoto T (1992) Specific expressions of Fyn and Lyn, lymphocyte antigen receptor- associated tyrosine kinases, in the central nervous system. Brain Res Mol Brain Res 16:303-310.

Umemori H, Ogura H, Tozawa N, Mikoshiba K, Nishizumi H, Yamamoto T (2003) Impairment of N-methyl-D-aspartate receptor-controlled motor activity in LYN-deficient mice. Neuroscience 118:709-713.

Ungless MA, Argilli E, Bonci A (2010) Effects of stress and aversion on dopamine neurons: implications for addiction. Neurosci Biobehav Rev 35:151-156.

Wang XQ, Yu SP (2005) Novel regulation of Na, K-ATPase by Src tyrosine kinases in cortical neurons. J Neurochem 93:1515-1523.

Wu X, Zhu D, Jiang X, Okagaki P, Mearow K, Zhu G, McCall S, Banaudha K, Lipsky RH, Marini AM (2004) AMPA protects cultured neurons against glutamate excitotoxicity through a phosphatidylinositol 3-kinasedependent activation in extracellular signal-regulated kinase to upregulate BDNF gene expression. J Neurochem 90:807-818.

Xiao W, Ando T, Wang HY, Kawakami Y, Kawakami T (2010) Lyn- and PLC-\{beta\}3-dependent regulation of SHP-1 phosphorylation controls Stat5 activity and myelomonocytic leukemia-like disease. Blood 116: 6003-6013.

Xu Y, Harder KW, Huntington ND, Hibbs ML, Tarlinton DM (2005) Lyn tyrosine kinase: accentuating the positive and the negative. Immunity 22:9-18. 